\section{INTELIGÊNCIA EMOCIONAL}

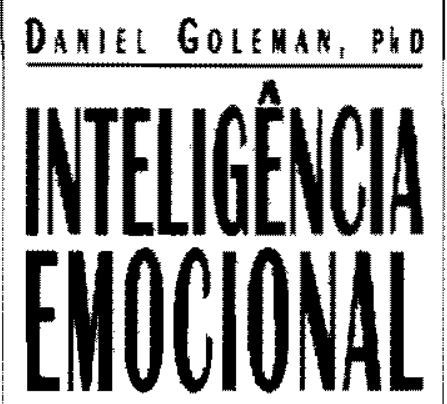

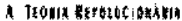

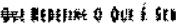

IMTELGENTE

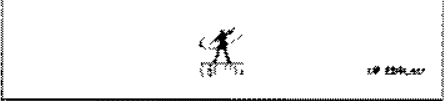

de DANIEL GOLEMAN

trad. Marcos Santarrita. Rio de Janeiro: Objetiva, 1995, 375 p.

por Cecília Whitaker Bergamini, Professora do Departamento de Administraçăo e Recursos Humanos da EAESP/FGV.

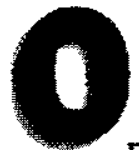

O livro de Goleman explora um dos aspec* tos mais questionáveis no estudo da personalidade humana. Assim, as emoçoes sofreram, ao longo dos tempos, inúmeras interpretações, de acordo com o pensamento dominante que cada escola interpretava das açóes humanas passíveis de observação. De forma bastante ousada, o autor, psicólogo formado pela Universidade de Harvard, faz uma reconciliação entre duas funçöes psíquicas que, historicamente, na época da psicologia filosófica, eram consideradas como absolutamente distintas, que são: inteligência e emoções.

Na época em que não existia ainda a opção de especialização universitária em psicologia, idos dos anos 60, essa área do conhecimento humano era estudada nos cursos de Filosofia e Pedagogia. No enfoque filosófico dos estudos de psicologia feito pelos antigos pensadores, essas duas funçôes psíquicas tinham características particulares que não poderiam jamais se confundir, pois eram consideradas como qualitativamente difenentes em sua natureza essencial. Com a evolução dos conceitos da psicologia, a distância entre esses dois conceitos vai aos poucos se encurtando e grande parte das obras passa a discutir a influência da inteligência sobre as emoçóes e vice-versa. Todavia, a função psíquica emocional não seria ainda confundida com um tipo de exercício intelectual.

Apesar dessa clara dístinção, não há uma razão suficiente para desabonar a obra que tanto sucesso está fazendo no mundo das publicaçốes sobre comportamento humano; pelo contrário, não há evidências de que essa obra contenha algum grave pecado contra a posição da ciência enquanto tal. Falar ao mesmo tempo de dois temas que convencionalmente foram sempre tratados a fim de se assemelharem a líquidos de densidades diferentes que nunca se misturam parece, da forma como Goleman o fez, alguma coisa que faz sentido e enriquece a compreensão do ser humano em sua maneira existencial de ser.

Por năo ser passivel de pesquisa objetiva, a abordagem experimental das emoções permaneceu, por muito tempo, pouco explorada. Muito das fontes de informaçăo sobre a natureza e a psicodinầmica emocional do homem foi obtido por meio daquilo que principalmente as obras de arte pareciam informar sobre quem as produziu. Sendo considerada um dos capítulos dos estudos cobertos pela Psicologia Geral, a emoção era estudada de forma descritiva e muito pouco era dito sobre aquilo que hoje se atribui a estados afetivos como fontes de ajustamento do homem perante seus conflitos existenciais. Muito pouco se conseguiu avançar nesse campo, principalmente quando se confronta com aquilo que jấ se conhecia sobre outras funçö́es psíquicas.

Especialmente após o período que se seguiu à Segunda Grande Guerra Mundial, a eminente necessidade que se passou a ter em recrutar e colocar um enorme contigente de trabalhadores especializados, a inteligência, assim como outras diferentes aptidoes mentais, foram decisivamente rastreadas. Nesse momento, o mais importante seria desenvolver um instrumental cientificamente válido por meio do qual se poderia viabilizar uma metodologia avaliativa para que se pudesse oferecer condiçōes de prever o rendimento e o futuro sucesso funcional daquelas pessoas que se dirigiam para as fábricas e escritórios do pós-guerra.

Por outro lado, momentos de pleno incentivo e valorização da racionalidade humana colocaram praticamente de quarentena a valorização do emocional. Isso atrasou mais ainda o avanço dos estudos sobre as emoçoes. A área dos estudos e das emoçōes parece ter-se transformado em um sítio em que o acesso estava claramente bloqueado.

Isso se deu, quase que exclusivamente, pelo encantamento do homem moderno por sua capacidade de resolução de problemas concretos, ou mais corretamente dizendo, por suas habilidades intelectuais.

Não apenas as organizações de trabalho mas principaimente os centros de ensino, desde o nível mais elementar até aqueles mais avançados, embrenharam-se, com surpreendente afinco, pelo campo intelectual adentro. O potencial de inteligência divulgado como o Q.I. (Quociente Intelectual), termo cunhado por Binet na França, comandava a maioria dos critérios de escolha de alunos no início e meados deste século. Além disso, todos os procedimentos educacionais deveriam, sobretudo, atender ao requisito de instrumento eficaz de treinamento das potencialidades intelectuais dos alunos. $O$ valor das pessoas passou a ser auferido pelo potencial de rendimento dos seus recursos intelectuais.

$O$ livro de Goleman chama a atenção do leitor para um tipo diferente de trabalho intelectual que é, segundo 
ele, o potencial de sucesso que cada um tem ao se defrontar com situações de relacionamento interpessoal. Talvez seja este o maior mérito dos temas desenvolvidos em Inteligência Emocional. Com isso, o autor parece, sem dúvida alguma, ter conseguido uma proposição menos míope da natureza humana. Como é proposto pelo autor, é mediante a autoconsciência que cada um será capaz de lidar, de forma mais eficiente, com aqueles sentimentos que mais afligem as pessoas, conseguindo, assirn, conservar o otimismo, além de estar capacitado a enfrentar as frustraçóes com perseverança, o que leva a um aumento da capacidade de empatia, envolvimento e cooperação no relacionamento social.

No livro, a emoção é considerada como um impulso para agir. A inteligência entocional é, portanto, constituída de talentos, tais como a capacidade de motivar-se e persistir diante das dificuldades, controlando os impulsos de forma a adiar a satisfação com o objetivo de regular o próprio estado de espírito impedindo que a afliçào invada a capacidade de pensar; criar empatia e esperar. Essa propriedade intelectual abrange um tipo diferente de inteligência; isto é, não se está mais falando apenas de inteligência considerada puramente do ponto de vista acadêmico. Esse tipo de especial função intelectual, quando bem desenvolvida, leva as pessoas a se sentirem satisfeitas e serem eficientes em suas vidas por terem desenvolvido a sua capacidade de dominar os hábitos mentais para chegarem à produtividade. Por outro lado, aquelas pessoas que não conseguem exercer nenhum tipo de controle sobre sua vida emocional consomem-se em batalhas interiores que desgastam essa capacidade de se concentrar no trabalho e pensar com clareza.

O autor aceita o ponto de vista de Gardner que muito claramente conceitua os dois aspectos mais importantes dos temas trabalhados no livro: a inteligência interpessoal concebida como a capacidade de compreender outras pessoas, com relação àquilo que as motiva, como trabalham, como conviver cooperativamente com elas. Pessoal de vendas, políticos, professores, clínicos e líderes religiosos bem-sucedidos provavelmente sejam todos individuos dotados de alto grau de inteligência interpessoal. Esse tipo de aptidão psíquica representa uma aptidão correlata, voltada para dentro. É a capacidade de formar um modelo preciso, de si mesmo, usando-o ao agir eficazmente na vida. Näo se pode dizer que a psicologia clássica tenha esquecido essas duas facetas do trabalho intelectual; a grande dificuldade de estudálas liga-se ao modo de avaliä-las por meio de testes confiâveis.

Propondo que o ser humano seja basicamente um ser emocional, a inteligência, como é descrita no livro, seria aquela ínstäncia do psiquismo humano capaz de controlar as emoçōes ditas perturbadores, aspecto fundamental ao bem-estar emocional de cada pessoa, de maneira geral. $\hat{E}_{z}$ portanto, a inteligência emocional de cada pessoa que tem como função devolver a estabilidade psíquica quando as emoçôes sầ muitos intensas e assim permanecem por tempo demasiado. Desse modo, admite o autor, aquelas pessoas que têm fortes episódios de ira e depressão ainda sentem uma sensação de bemestar para contrabalançar um conjunto de momentos igualmente alegres e felizes.

Inteligência Emocional estă subdividido em cinco partes, sendo que as três primeiras prendem a atenção do leitor não somente por seu conteúdo, como tambêm por apresentarem uma linha lógica de desencadeamento dos temas muito interessante. $O$ conteúdo do livro fica valorizado pela tradução que, sem dúvida, é muito boa, deixando claro que o tradutor maneja com bastante propriedade a terminologia utilizada pelas ciências humanas. Essas três partes iniciais cobrem temas como: o cérebro emocional, a natureza da inteligencia emocional e inteligência emocional aplicada, ressaltando-se que a cabeça e o coração precisam um do outro principalmente nestes tempos complexos e de mudanças aceleradas.

Infelizmente, o ritmo inicial vai se perdendo após esses primeiros capitulos, e o autor passa a se repetir demais quando entra em medidas que possam viabilizar o treinamento do aspecto emocional referido nos últimos capítulos da obra. A última parte, então, parece tirar um pouco do valor oferecido pela postura científica da obra quando se passa para um tipo de repertório de medidas práticas e receitas do que fazer.

As duas partes finais não acompanham as iniciais que parecem ter primado pelo enfoque científico, principalmente na parte dois, na qual as proposições do autor são fundadas na neurologia e farmacologia do sistema nervoso central. Seria desejável cortar a redundância desses temas e que o autor se limitasse a não oferecer uma espécie de pacote de treinamento pronto a ser consumido por quem quer que seja. Parece entăo que, no final de sua obra, Goleman se esquece de um conceito que está sempre presente no início do seu trabalho que é: aqueles que admitem as diferenças individuais, esquecem que a via de desenvolvimento dessa aptidão intelectual pode variar de pessoa para pessoa. Portanto, seus conselhos não podem, como ele mesmo propõe, constituir-se em recursos de cura para quaisquer males. Caso o leitor não se proponha a seguir o roteiro de desenvolvimento pessoal colocado nessas últimas duas partes, ele pode ficar com a mais importante mensagem que o livro se propõe a transmitir.

Bastaria, para um grande final, que Goleman tivesse se limitado a esclarecer como as emoçóes podem contribuir, dificultar ou impedir o equilibrio interno das pessoas. Nas palavras de Goleman: "na medida em que nossas emoçöes atrapalham ou aumentam nossa capacidade de pensar e fazer planos, de seguir treinando para alcançar uma meta distante, solucionar problemas e coisas assim, definem os $i$ mites do nosso poder de usar nossas capacidades mentais inatas, eassim determinam como nos saimos na vida. $E_{\text {, na medi- }}$ da ew que somos motivados por sentimentos de entusiasmo $e$ prazer no que fazemos - ou mesmo por um grat ideal deansiedade, esses sentimentos nos levam ì conquista. É nesse sentido que a inteligência enocional é uma aptidão mestra, uma capacidade que afela profundamente todas as outras facilitando ou interferindo com elas ${ }^{*}$. Eé por isso que o livro vale ser lido. 